\title{
Effect of Temperature on Equilibria in Synthetic Sulfuric Acid Leaching Solution of Zinc Calcine
}

\author{
Man-Seung Lee ${ }^{1, *}$, Kyoung-Ju Lee ${ }^{1}$ and Young-Joo $\mathrm{Oh}^{2}$ \\ ${ }^{1}$ Department of Advanced Materials Science and Engineering, Mokpo National University, Chonnam 534-729, Korea \\ ${ }^{2}$ Metal Processing Research Center, Korea Institute of Science and Technology, P.O. Box 131, Cheongryang, Seoul, Korea
}

\begin{abstract}
In order to simulate the leaching of zinc calcine by sulfuric acid solutions, we prepared synthetic solutions with the composition $\mathrm{ZnSO}_{4}$ $\mathrm{Fe}_{2}\left(\mathrm{SO}_{4}\right)_{3}-\mathrm{Na}_{2} \mathrm{SO}_{4}-\mathrm{H}_{2} \mathrm{SO}_{4}-\mathrm{NaOH}-\mathrm{H}_{2} \mathrm{O}$ and measured the solution $\mathrm{pH}$ at various temperatures. The effect of temperature on the ionic equilibria of these solutions was analyzed by considering chemical equilibria, mass balance and charge balance equations. The activity coefficients of solutes and the activity of water were calculated by using the Pitzer equation. The mole fractions of iron species were greatly affected by the solution temperature and the concentration of $\mathrm{Fe}_{2}\left(\mathrm{SO}_{4}\right)_{3}$. In the experimental ranges of ionic strength of solution up to $9 \mathrm{~m}$, the pH values calculated in this study agreed well with those measured.
\end{abstract}

(Received December 8, 2003; Accepted March 1, 2004)

Keywords: zinc calcine, leaching, sulfuric acid, ionic equilibria, Pitzer, temperature

\section{Introduction}

In zinc hydrometallurgy, a neutral leach residue is treated with strong sulfuric acid solution at high temperatures. Ferric ions are leached together with zinc ions in this hot acid treatment step. Iron ions in the leach solution are removed by precipitation process, such as the Jarosite and Goethite processes. During the dumping of these precipitates, heavy metals are leached out together with iron ions and this leads to an environmental problem. Studies have been made on processes, which employ solvent extraction to recover iron selectively from the leaching solution. Control of solution $\mathrm{pH}$ and knowledge of the data on the distribution of chemical species are very important in developing a process for the recovery of iron from the zinc sulfate solution. ${ }^{1-3)}$

In electrolyte solutions, the formation and activity coefficients of chemical complexes affect ionic equilibria of a solution. The distribution of chemical complexes depends on the conditions of electrolyte solution, such as composition and temperature. This distribution can be analyzed by considering chemical equilibria, mass and charge balance equations. Several equations have been developed to calculate the activity coefficients of solutes and water activity. ${ }^{4)}$ Among these equations, the extended Debye-Hückel and Davies equations are useful in calculating activity coefficients of ions for solutions in which ionic strength is less than 0.1 molal and the ions are non-associative. ${ }^{4)}$

At high ionic strength, Pitzer and Bromely equations are widely used owing to the availability of the parameter necessary in calculating the activity coefficient of ions. Few data on the activity coefficient of ferric ion, however, have been reported. Lack of the data on the activity coefficient of ferric ion has made it difficult to consider the nonideality of ferric species in the aqueous phase. Fairly recently, the interaction parameter of $\mathrm{Fe}\left(\mathrm{ClO}_{4}\right)_{3}$ at $25^{\circ} \mathrm{C}$ for the Pitzer equation was reported by Millero ${ }^{5)}$ and this parameter was used to obtain an interaction parameter of the ferric ion in the present study.
We developed a chemical model to analyze the effects of ionic strength and temperature on the ionic equilbria in the synthetic sulfuric acid solutions of zinc calcine. This model consists of chemical equilibria and mass and charge balance equations. Activity coefficients of solutes and water activity were calculated by using the Pitzer equation. By applying this model, we analyzed the distribution of zinc and iron species with the composition and temperature of a synthetic solution. To check the validity of this model, the experimental $\mathrm{pH}$ values at 25,50 and $75^{\circ} \mathrm{C}$ were compared with those calculated in this study.

\section{Thermodynamic Model}

The $\mathrm{ZnSO}_{4}-\mathrm{Fe}_{2}\left(\mathrm{SO}_{4}\right)_{3}-\mathrm{H}_{2} \mathrm{SO}_{4}-\mathrm{NaOH}-\mathrm{H}_{2} \mathrm{O}$ system was prepared for the simulation of leaching solutions of zinc calcine. Sodium sulfate was added to increase the ionic strength of the synthetic solution. The distribution of zinc species depends on the total zinc concentration, ionic medium, $\mathrm{pH}$ and temperature of the solution. It is only when the $\mathrm{pH}$ value of the solution is higher than 8 that $\mathrm{Zn}(\mathrm{OH})_{3}{ }^{-}$ and $\mathrm{Zn}(\mathrm{OH})_{4}{ }^{2-}$ appear in the solution. ${ }^{6,7)} \mathrm{We}$ therefore do not consider these complexes. We also assumed that $\mathrm{H}_{2} \mathrm{SO}_{4}$ was dissociated into hydrogen and bisulfate ions completely. Table 1 shows complex formation reactions considered in this study and the equilibrium constants at $25^{\circ} \mathrm{C}, \mathrm{K}_{298}{ }^{2,6,8)}$ These values in Table 1 represent the equilibrium constants at zero ionic strength. The equilibrium constants other than $25^{\circ} \mathrm{C}, K_{\mathrm{T}}$, were calculated by the following Van't Hoff equation. In integrating this equation, changes in the values of the standard enthalpy for each chemical reaction, $\Delta H^{\circ}$, were assumed to be constant. The standard enthalpy changes for each chemical reaction are also shown in Table 1.

$$
\ln K_{\mathrm{T}}-\ln K_{298}=-\frac{\Delta H^{\circ}}{R}\left(\frac{1}{T}-\frac{1}{298}\right)
$$

The following mass and charge balance equations were obtained from the chemical equilibria. 
Table 1 Thermodynamic data of various complex formation reaction.

\begin{tabular}{|c|c|c|c|}
\hline Reaction & $\log K_{298}$ & $\begin{array}{c}\Delta H_{298}^{\circ} \\
(\mathrm{kJ} / \mathrm{mol})\end{array}$ & Reference \\
\hline $\mathrm{H}^{+}+\mathrm{OH}^{-}=\mathrm{H}_{2} \mathrm{O}$ & 14.00 & -55.73 & 2 \\
\hline $\mathrm{H}^{+}+\mathrm{SO}_{4}^{2-}=\mathrm{HSO}_{4}^{-}$ & 1.99 & 22.17 & 2 \\
\hline $\mathrm{Fe}^{3+}+\mathrm{SO}_{4}^{2-}=\mathrm{FeSO}_{4}^{+}$ & 4.13 & 25.9 & 2 \\
\hline $\mathrm{Fe}^{3+}+2 \mathrm{SO}_{4}^{2-}=\mathrm{Fe}\left(\mathrm{SO}_{4}\right)_{2}^{-}$ & 5.40 & 38.47 & 2 \\
\hline $\mathrm{Fe}^{3+}+\mathrm{HSO}_{4}^{-}=\mathrm{Fe}\left(\mathrm{HSO}_{4}\right)^{2+}$ & 1.36 & 41.22 & 2 \\
\hline $\mathrm{Fe}^{3+}+\mathrm{OH}^{-}=\mathrm{FeOH}^{2+}$ & 11.83 & -12.18 & 2 \\
\hline $\mathrm{Fe}^{3+}+2 \mathrm{OH}^{-}=\mathrm{Fe}(\mathrm{OH})_{2}^{+}$ & 22.30 & -35.06 & 2 \\
\hline $\mathrm{Fe}^{3+}+3 \mathrm{OH}^{-}=\mathrm{Fe}(\mathrm{OH})_{3}^{\circ}$ & 32.17 & -56.87 & 2 \\
\hline $\mathrm{Na}^{+}+\mathrm{SO}_{4}^{2-}=\mathrm{NaSO}_{4}^{-}$ & 0.76 & 4.6 & 8 \\
\hline $\mathrm{Zn}^{2+}+\mathrm{SO}_{4}{ }^{2-}=\mathrm{ZnSO}_{4}{ }^{\circ}$ & 2.32 & 15.85 & 2 \\
\hline $\mathrm{Zn}^{2+}+\mathrm{OH}^{-}=\mathrm{ZnOH}^{+}$ & 4.51 & 21.09 & 6 \\
\hline $\mathrm{Zn}^{2+}+2 \mathrm{OH}^{-}=\mathrm{Zn}(\mathrm{OH})_{2}{ }^{\circ}$ & 10.71 & -25.83 & 6 \\
\hline
\end{tabular}

$$
\begin{aligned}
{[\mathrm{Fe}]_{\mathrm{t}}=} & 2\left[\mathrm{Fe}_{2}\left(\mathrm{SO}_{4}\right)_{3}\right]_{\mathrm{t}} \\
= & {\left[\mathrm{Fe}^{3+}\right]+\left[\mathrm{FeSO}_{4}{ }^{+}\right]+\left[\mathrm{Fe}\left(\mathrm{SO}_{4}\right)_{2}{ }^{-}\right] } \\
& +\left[\mathrm{FeHSO}{ }_{4}{ }^{2+}\right]+\left[\mathrm{FeOH}{ }^{2+}\right] \\
& +\left[\mathrm{Fe}(\mathrm{OH})_{2}{ }^{+}\right]+\left[\mathrm{Fe}(\mathrm{OH})_{3}{ }^{\circ}\right]
\end{aligned}
$$

where [i] represents the concentration of i species.

$$
\begin{aligned}
{[\mathrm{Na}]_{\mathrm{t}}=} & 2\left[\mathrm{Na}_{2} \mathrm{SO}_{4}\right]_{\mathrm{t}}+[\mathrm{NaOH}]_{\mathrm{t}}=\left[\mathrm{Na}^{+}\right]+\left[\mathrm{NaSO}_{4}{ }^{-}\right] \\
{[\mathrm{S}]_{\mathrm{t}}=} & 3\left[\mathrm{Fe}_{2}\left(\mathrm{SO}_{4}\right)_{3}\right]_{\mathrm{t}}+\left[\mathrm{Na}_{2} \mathrm{SO}_{4}\right]_{\mathrm{t}}+\left[\mathrm{H}_{2} \mathrm{SO}_{4}\right]_{\mathrm{t}}+\left[\mathrm{ZnSO}_{4}\right]_{\mathrm{t}} \\
= & {\left[\mathrm{SO}_{4}{ }^{2-}\right]+\left[\mathrm{HSO}_{4}{ }^{-}\right]+\left[\mathrm{FeSO}_{4}{ }^{+}\right]+2\left[\mathrm{Fe}\left(\mathrm{SO}_{4}\right)_{2}{ }^{-}\right] } \\
& +\left[\mathrm{FeHSO}_{4}{ }^{2+}\right]+\left[\mathrm{NaSO}_{4}{ }^{-}\right]+\left[\mathrm{ZnSO}_{4}{ }^{\circ}\right] \\
{[\mathrm{Zn}]_{\mathrm{t}}=} & {\left[\mathrm{ZnSO}_{4}\right]_{\mathrm{t}}=\left[\mathrm{Zn}^{2+}\right]+\left[\mathrm{ZnSO}_{4}^{\circ}\right] } \\
& +\left[\mathrm{ZnOH}^{+}\right]+\left[\mathrm{Zn}(\mathrm{OH})_{2}{ }^{\circ}\right]
\end{aligned}
$$

$\left[\mathrm{H}^{+}\right]+3\left[\mathrm{Fe}^{3+}\right]+\left[\mathrm{FeSO}_{4}{ }^{+}\right]+2\left[\mathrm{FeHSO}_{4}{ }^{2+}\right]+2\left[\mathrm{FeOH}^{2+}\right]$

$$
\begin{aligned}
+ & {\left[\mathrm{Fe}(\mathrm{OH})_{2}{ }^{+}\right]+\left[\mathrm{Na}^{+}\right]+2\left[\mathrm{Zn}^{2+}\right]+\left[\mathrm{ZnOH}^{+}\right] } \\
= & {\left[\mathrm{HSO}_{4}^{-}\right]+\left[\mathrm{Fe}\left(\mathrm{SO}_{4}\right)_{2}^{-}\right] } \\
& +\left[\mathrm{NaSO}_{4}^{-}\right]+\left[\mathrm{OH}^{-}\right]+2\left[\mathrm{SO}_{4}{ }^{2-}\right]
\end{aligned}
$$

where the subscript $t$ represents the total concentration.

The activity coefficient of $i, \gamma_{i}$, is expressed by the modified Pitzer equation as follows ${ }^{9}$

$$
\ln \gamma_{\mathrm{i}}=z_{\mathrm{i}}^{2} f^{\gamma}+2 \sum_{\mathrm{j} \neq \mathrm{H}_{2} \mathrm{O}} m_{\mathrm{j}} B_{\mathrm{ij}}+\sum_{\mathrm{j} \neq \mathrm{H}_{2} \mathrm{O}} \sum_{\mathrm{k} \neq \mathrm{H}_{2} \mathrm{O}} m_{\mathrm{j}} m_{\mathrm{k}} z_{\mathrm{i}}^{2} B_{\mathrm{jk}}^{\prime}
$$

where $Z_{\mathrm{i}}$ denotes charge number of ion $\mathrm{i}$.

$$
\begin{aligned}
& f^{\gamma}=-A_{\phi}\left[\frac{\sqrt{I}}{1+1.2 \sqrt{I}}+\frac{2}{1.2} \ln (1+1.2 \sqrt{I})\right] \\
& B_{\mathrm{ij}}=\beta_{\mathrm{ij}}^{0}+\frac{\beta_{\mathrm{ij}}^{1}}{2 I}[1-(1+2 \sqrt{I}) \exp (-2 \sqrt{I})] \\
& B_{\mathrm{jk}}^{\prime}=\frac{\beta_{\mathrm{ij}}^{1}}{2 I^{2}}[-1+(1+2 \sqrt{I}+2 I) \exp (-2 \sqrt{I})]
\end{aligned}
$$

In the above equations, $A_{\phi}$ represents Debye-Hückel constant, $I$ ionic strength of the solution and $m$ molality of the chemical species. And $\beta_{\mathrm{ij}}^{0}$ and $\beta_{\mathrm{ij}}^{1}$ represent the interaction parameter between $\mathrm{i}$ and $\mathrm{j}$.

The activity of water was calculated by the following Pitzer equation. ${ }^{10)}$

$$
\begin{aligned}
\ln a_{\mathrm{w}}= & -\frac{M_{\mathrm{w}}}{1000}\left(\sum_{\mathrm{i} \neq \mathrm{H}_{2} \mathrm{O}} m_{\mathrm{i}}\right) \phi \\
\phi-1= & \frac{2}{\sum_{\mathrm{i} \neq \mathrm{H}_{2} \mathrm{O}} m_{\mathrm{i}}}\left[-\frac{A_{\phi} I^{3 / 2}}{1+1.2 \sqrt{I}}+\sum_{\mathrm{i} \neq \mathrm{H}_{2} \mathrm{O}} \sum_{\mathrm{j} \neq \mathrm{H}_{2} \mathrm{O}}\right. \\
& \left.\times m_{\mathrm{i}} m_{\mathrm{j}}\left\{\beta_{\mathrm{ij}}^{0}+\beta_{\mathrm{ij}}^{1} \exp (-2 \sqrt{I})\right\}\right]
\end{aligned}
$$

where $M_{\mathrm{w}}$ and $\phi$ represent the molecular weight and the osmotic coefficient of water, respectively.

\section{Experimental}

The synthetic solutions were prepared by dissolving $\mathrm{ZnSO}_{4}, \mathrm{Fe}_{2}\left(\mathrm{SO}_{4}\right)_{3}, \mathrm{Na}_{2} \mathrm{SO}_{4}, \mathrm{H}_{2} \mathrm{SO}_{4}$ and $\mathrm{NaOH}$ in distilled water. All reagents were of analytical grade. First, known amounts of reagents were added to $100 \mathrm{~g}$ of water and the mixture was stirred for 30 minutes with a magnetic stirrer. After the reagents were dissolved, the temperature of solution was controlled in a water bath(Jeio Tech, SWB-03 Shaking Water Bath). All $\mathrm{pH}$ values of the solutions were measured with a $\mathrm{pH}$ meter(Orion 920A). The electrode was calibrated by the three-point method before every $\mathrm{pH}$ measurement.

\section{Results and Discussion}

\subsection{Estimation of interaction parameter}

Table 2 shows the interaction parameters $\beta_{\mathrm{MX}}^{0}$ and $\beta_{\mathrm{MX}}^{1}$ at $25^{\circ} \mathrm{C}$ for strong electrolytes reported by Pitzer and Millero. ${ }^{5,11)}$ The mean activity coefficients of strong electrolytes could be calculated by inserting these interaction parameters into the Pitzer equation. In order to calculate the activity coefficients of individual ions, the interaction parameters of the individual ions are needed. Edwards assumed that the interaction parameter $\beta_{\mathrm{MX}}^{0}$ was equal to the sum of the interaction parameters of the individual ions. ${ }^{12)}$

$$
\beta_{\mathrm{MX}}^{0}=\beta_{\mathrm{M}}^{0}+\beta_{\mathrm{X}}^{0}
$$

Edwards obtained $\beta^{0}$ and $\beta^{1}$ of the individual ions from $\beta_{\mathrm{MX}}^{0}$ and $\beta_{\mathrm{MX}}^{1}$ by setting $\beta_{\mathrm{Na}^{+}}^{0}$ and $\beta_{\mathrm{Na}^{+}}^{1}$ equal to zero. In this study, Edwards' estimation method was used to obtain the interaction parameters $\beta^{0}$ and $\beta^{1}$ of the individual ions. The interaction parameters between ion and molecule and between molecule and molecule were obtained by the following Edwards' approximation equations.

Table 2 Interaction parameters of electrolytes at $25^{\circ} \mathrm{C}$.

\begin{tabular}{lllc}
\hline \multicolumn{1}{c}{ Species } & \multicolumn{1}{c}{$\beta^{0}$} & $\beta^{1}$ & Reference \\
\hline $\mathrm{HCl}$ & 0.1775 & 0.2945 & 11 \\
\hline $\mathrm{Fe}\left(\mathrm{ClO}_{4}\right)_{3}$ & 1.412 & 2.989 & 5 \\
\hline $\mathrm{NaCl}$ & 0.0765 & 0.2664 & 11 \\
\hline $\mathrm{NaClO}$ & 0.0554 & 0.2755 & 11 \\
\hline $\mathrm{NaOH}$ & 0.0864 & 0.253 & 11 \\
\hline $\mathrm{Na}_{2} \mathrm{SO}_{4}$ & 0.01958 & 1.113 & 11 \\
\hline $\mathrm{ZnSO}_{4}$ & 0.1949 & 2.883 & 11 \\
\hline
\end{tabular}


Table 3 Temperature derivatives of the Pitzer parameter in the temperature range between 0 and $100^{\circ} \mathrm{C}$.

\begin{tabular}{lcc}
\hline Species & $\left(\frac{\partial \beta^{0}}{\partial T}\right)_{\mathrm{P}} \times 10^{4}$ & $\left(\frac{\partial \beta^{1}}{\partial T}\right)_{\mathrm{P}} \times 10^{4}$ \\
\hline $\mathrm{HCl}$ & -3.081 & 1.419 \\
\hline $\mathrm{LaCl}_{3}$ & 0.253 & 0.798 \\
\hline $\mathrm{NaCl}$ & 7.159 & 7.005 \\
\hline $\mathrm{NaClO}$ & 12.96 & 22.97 \\
\hline $\mathrm{NaOH}_{4}$ & 7.00 & 1.34 \\
\hline $\mathrm{Na}_{2} \mathrm{SO}_{4}$ & 3.156 & 7.51 \\
\hline $\mathrm{ZnSO}_{4}$ & -3.66 & 2.33 \\
\hline
\end{tabular}

$$
\begin{aligned}
\beta_{\text {ion-molecule }}^{0} & =\beta_{\text {ion }}^{0}+\beta_{\text {molecule }}^{0} \\
\beta_{\mathrm{ij}}^{0} & =0.5\left(\beta_{\mathrm{i}}^{0}+\beta_{\mathrm{j}}^{0}\right)
\end{aligned}
$$

Temperature derivatives of the interaction parameters in the temperature range between 0 and $100^{\circ} \mathrm{C}$ are obtained from the data reported by Pitzer and shown in Table 3. ${ }^{11}$ ) Among temperature derivatives of Pitzer parameter, only values for $\mathrm{LaCl}_{3}, \mathrm{La}\left(\mathrm{ClO}_{4}\right)_{3}, \mathrm{La}\left(\mathrm{NO}_{3}\right)_{3}, \mathrm{Na}_{3} \mathrm{Fe}(\mathrm{CN})_{6}$ and $\mathrm{K}_{3} \mathrm{Fe}(\mathrm{CN})_{6}$ are available for 3-1 electrolytes. Temperature derivatives of Pitzer parameter for species containing lanthanum ion are within narrow range while those for $\mathrm{Na}_{3} \mathrm{Fe}(\mathrm{CN})_{6}$ and $\mathrm{K}_{3} \mathrm{Fe}(\mathrm{CN})_{6}$ are widely scattered. Therefore, the temperature derivative of $\mathrm{LaCl}_{3}$ was chosen for the value of $\mathrm{FeCl}_{3}$. The interaction parameters $\beta_{\mathrm{MX}}^{0}$ and $\beta_{\mathrm{MX}}^{1}$ at ambient temperature were calculated by the following equation.

$$
\int_{\beta_{298}}^{\beta_{\mathrm{T}}} \mathrm{d} \beta=\int_{298}^{T}\left(\frac{\partial \beta}{\partial T}\right)_{\mathrm{P}} \mathrm{d} T
$$

Table 4 shows the interaction parameter $\beta^{0}$ and $\beta^{1}$ of the individual ions at ambient temperature obtained in this study.

\subsection{Ionic equilibria analysis}

The number of chemical species at equilibrium is $18\left(\mathrm{Fe}^{3+}\right.$, $\mathrm{FeSO}_{4}{ }^{+}, \mathrm{Fe}\left(\mathrm{SO}_{4}\right)_{2}{ }^{-}, \mathrm{FeHSO}_{4}{ }^{2+}, \mathrm{FeOH}^{2+}, \mathrm{Fe}(\mathrm{OH})_{2}{ }^{+}$, $\mathrm{Fe}(\mathrm{OH})_{3}{ }^{\circ}, \mathrm{H}^{+}, \mathrm{HSO}_{4}{ }^{-}, \mathrm{Na}^{+}, \mathrm{NaSO}_{4}{ }^{-}, \mathrm{OH}^{-}, \mathrm{SO}_{4}{ }^{-}, \mathrm{Zn}^{2+}$, $\left.\mathrm{ZnSO}_{4}{ }^{\circ}, \mathrm{ZnOH}^{+}, \mathrm{Zn}(\mathrm{OH})_{2}{ }^{\circ}, \mathrm{H}_{2} \mathrm{O}\right)$. We need 35 independent equations to calculate the concentrations and the activity coefficients of 17 solutes and water activity. These equations consist of 12 chemical equilibria, 4 mass and 1 charge balance equations, 17 equations for the activity coefficients and the activity equation of water.

The initial concentrations of $\mathrm{Fe}^{3+}, \mathrm{Na}^{+}, \mathrm{Zn}^{2+}$ and $\mathrm{SO}_{4}{ }^{2-}$ are obtained from the assumption that the electrolytes

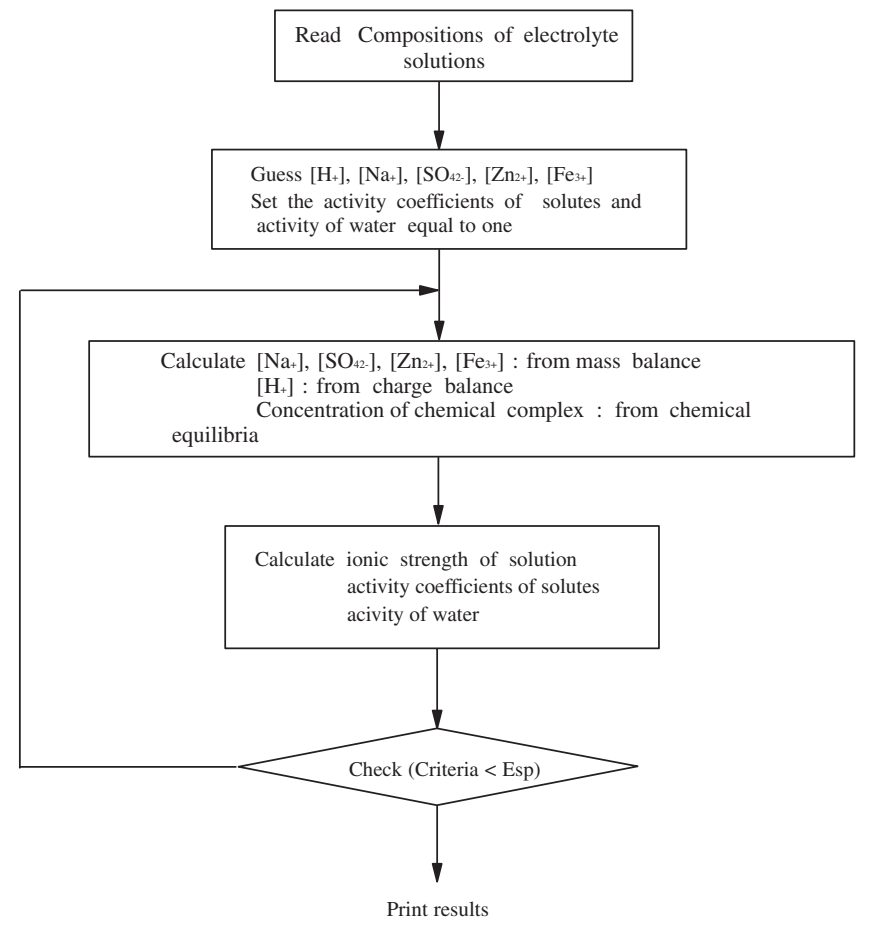

Fig. 1 Flowchart for the calculation of the equilibrium concentrations of solutes.

dissociated completely. The nonlinear equations were solved by Newton-Raphson method and the algorithm is shown in Fig. 1.

Since the leaching solutions of zinc calcine contain about $90 \mathrm{~g} / \mathrm{L}$ of zinc ion, $25 \mathrm{~g} / \mathrm{L}$ of ferric ion and $25 \mathrm{~g} / \mathrm{L}$ of $\mathrm{H}_{2} \mathrm{SO}_{4}$ in zinc hydrometallurgy, the composition of the synthetic solution was chosen as follows:

$$
\begin{aligned}
{\left[\mathrm{ZnSO}_{4}\right] } & =1.0 \mathrm{~mol} / \mathrm{kg},\left[\mathrm{Fe}_{2}\left(\mathrm{SO}_{4}\right)_{3}\right] \\
& =0.2 \mathrm{~mol} / \mathrm{kg},\left[\mathrm{H}_{2} \mathrm{SO}_{4}\right]=0.5 \mathrm{~mol} / \mathrm{kg},[\mathrm{NaOH}] \\
& =0.2 \mathrm{~mol} / \mathrm{kg}
\end{aligned}
$$

Figure 2 shows the distribution of zinc species with temperature. It is indicated in Fig. 2 that the mole fractions of $\mathrm{Zn}^{2+}$ and $\mathrm{ZnSO}_{4}{ }^{\circ}$ are constant in the temperature range between 20 and $90^{\circ} \mathrm{C}$ whereas those of $\mathrm{ZnOH}^{+}$and $\mathrm{Zn}(\mathrm{OH})_{2}{ }^{\circ}$ rise with increasing temperature. And the concentrations of $\mathrm{ZnOH}^{+}$and $\mathrm{Zn}(\mathrm{OH})_{2}{ }^{\circ}$ were negligible. The result of this calculation supported our assumption that $\mathrm{Zn}(\mathrm{OH})_{3}{ }^{-}$ and $\mathrm{Zn}(\mathrm{OH})_{4}{ }^{2-}$ did not exist in our experimental conditions.

Figure 3 shows the distribution of iron species with temperature. It is seen in Fig. 3 that the mole fraction of iron

Table 4 Variation of estimated values of ion interaction parameter with temperature.

\begin{tabular}{llr}
\hline Species & \multicolumn{1}{c}{$\beta^{0}$} & $\beta^{1}$ \\
\hline $\mathrm{H}^{+}$ & $0.101-10.24 \times 10^{-4}(T-298)$ & $0.0281-5.586 \times 10^{-4}(T-298)$ \\
\hline $\mathrm{La}^{3+}$ & $1.3566-6.906 \times 10^{-4}(T-298)$ & $2.7135-6.207 \times 10^{-4}(T-298)$ \\
\hline $\mathrm{Na}^{+}$ & 0.0 & 0.0 \\
\hline $\mathrm{Zn}^{2+}$ & $0.1753-6.816 \times 10^{-4}(T-298)$ & $1.77-5.18 \times 10^{-4}(T-298)$ \\
\hline $\mathrm{OH}^{-}$ & $0.0864+7.0 \times 10^{-4}(T-298)$ & $0.253+1.34 \times 10^{-4}(T-298)$ \\
\hline $\mathrm{SO}_{4}{ }^{2-}$ & $0.01958+3.156 \times 10^{-4}(T-298)$ & $1.113+7.51 \times 10^{-4}(T-298)$ \\
\hline
\end{tabular}




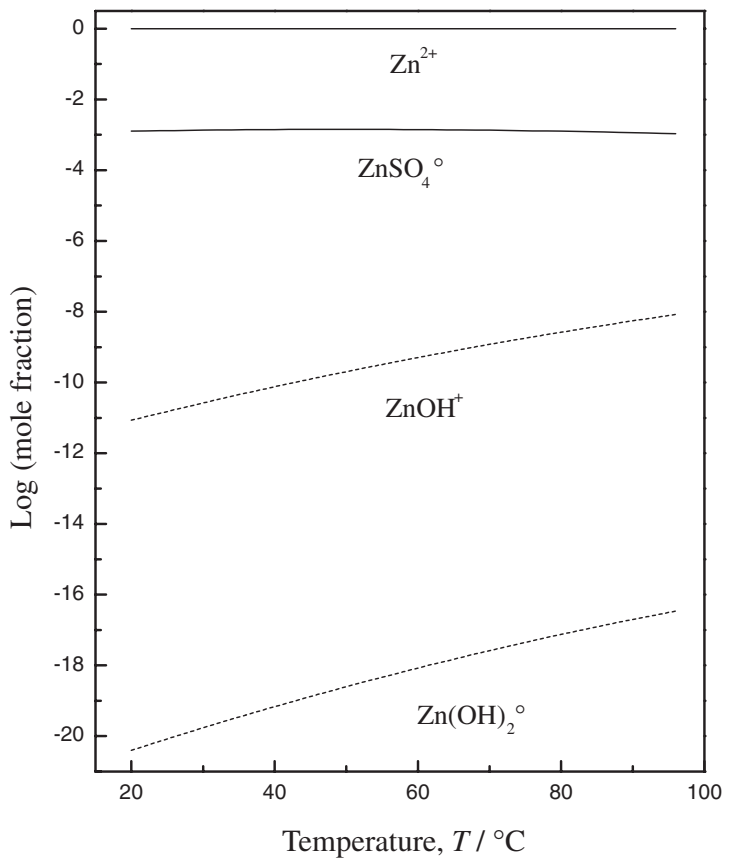

Fig. 2 Distribution of zinc species with temperature. ([ $\left.\mathrm{ZnSO}_{4}\right]_{\mathrm{t}}=1.0 \mathrm{~m}$, $\left.\left[\mathrm{Fe}_{2}\left(\mathrm{SO}_{4}\right)_{3}\right]_{\mathrm{t}}=0.2 \mathrm{~m},\left[\mathrm{H}_{2} \mathrm{SO}_{4}\right]_{\mathrm{t}}=0.5 \mathrm{~m},[\mathrm{NaOH}]_{\mathrm{t}}=0.3 \mathrm{~m}\right)$

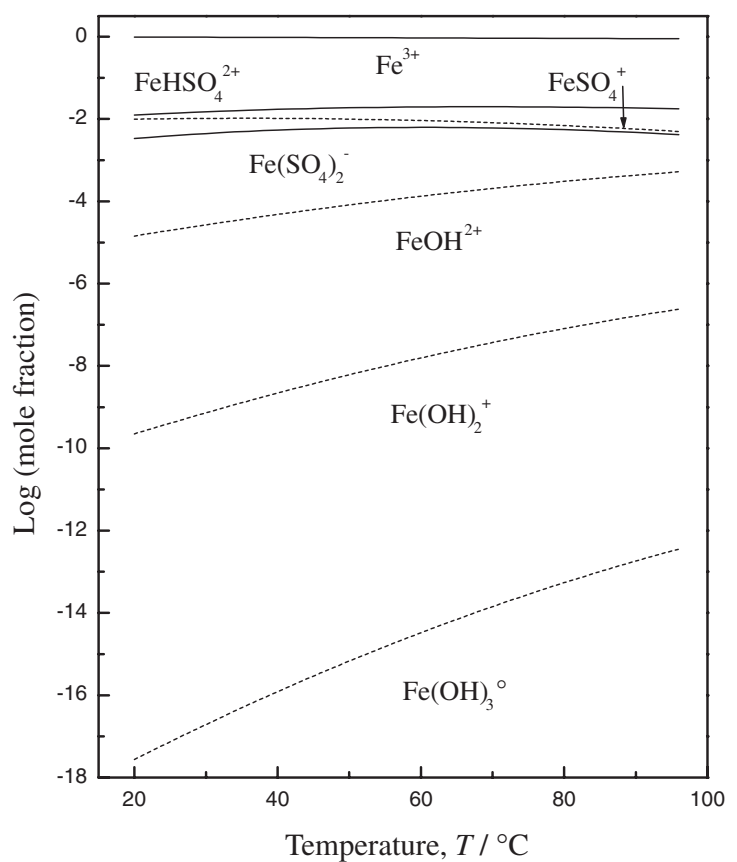

Fig. 3 Distribution of iron species with temperature. $\left(\left[\mathrm{ZnSO}_{4}\right]_{\mathrm{t}}=1.0 \mathrm{~m}\right.$, $\left.\left[\mathrm{Fe}_{2}\left(\mathrm{SO}_{4}\right)_{3}\right]_{\mathrm{t}}=0.2 \mathrm{~m},\left[\mathrm{H}_{2} \mathrm{SO}_{4}\right]_{\mathrm{t}}=0.5 \mathrm{~m},[\mathrm{NaOH}]_{\mathrm{t}}=0.3 \mathrm{~m}\right)$.

species decreases at constant temperature in the following order, $\mathrm{Fe}^{3+}>\mathrm{FeHSO}_{4}{ }^{2+}>\mathrm{FeSO}_{4}^{+}>\mathrm{Fe}\left(\mathrm{SO}_{4}\right)_{2}{ }^{-}>$ $\mathrm{FeOH}^{2+}>\mathrm{Fe}(\mathrm{OH})_{2}{ }^{+}>\mathrm{Fe}(\mathrm{OH})_{3}{ }^{\circ}$. Also it is known in Fig. 3 that the mole fractions of $\mathrm{Fe}^{3+}, \mathrm{FeHSO}_{4}{ }^{2+}, \mathrm{FeSO}_{4}{ }^{+}$and $\mathrm{Fe}\left(\mathrm{SO}_{4}\right)_{2}{ }^{-}$are almost constant in the temperature range. However, the mole fractions of $\mathrm{FeOH}^{2+}, \mathrm{Fe}(\mathrm{OH})_{2}{ }^{+}$and $\mathrm{Fe}(\mathrm{OH})_{3}{ }^{\circ}$ increased with increasing temperature. The reason why the mole fractions of zinc and iron hydroxide complexes increased was that the $\mathrm{pH}$ values increased with increasing

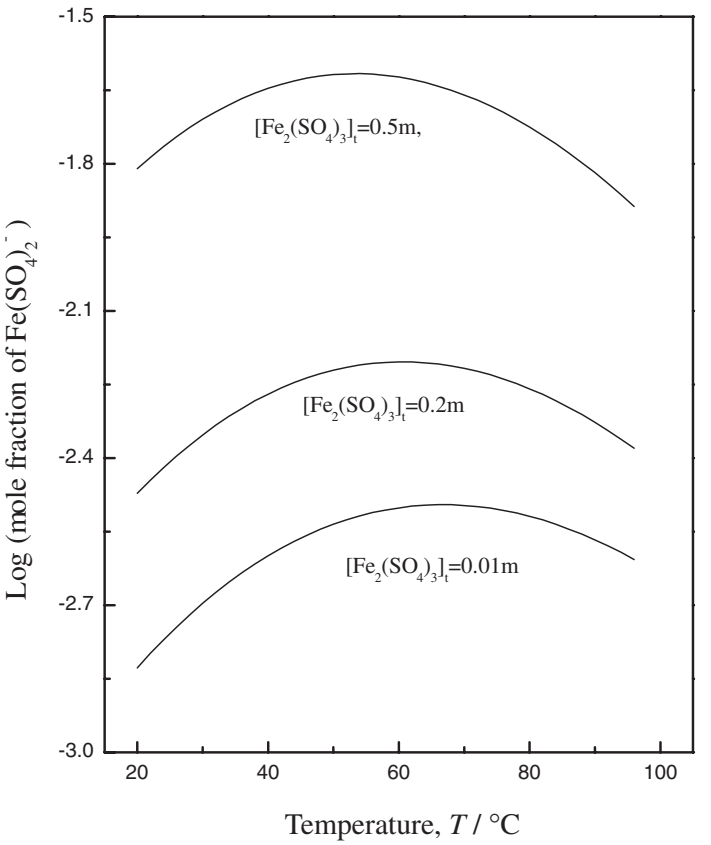

Fig. 4 Variation of mole fraction of $\mathrm{Fe}\left(\mathrm{SO}_{4}\right)_{2}{ }^{-}$with temperature. $\left(\left[\mathrm{ZnSO}_{4}\right]_{\mathrm{t}}=1.0 \mathrm{~m},\left[\mathrm{H}_{2} \mathrm{SO}_{4}\right]_{\mathrm{t}}=0.5 \mathrm{~m},[\mathrm{NaOH}]_{\mathrm{t}}=0.3 \mathrm{~m}\right)$.

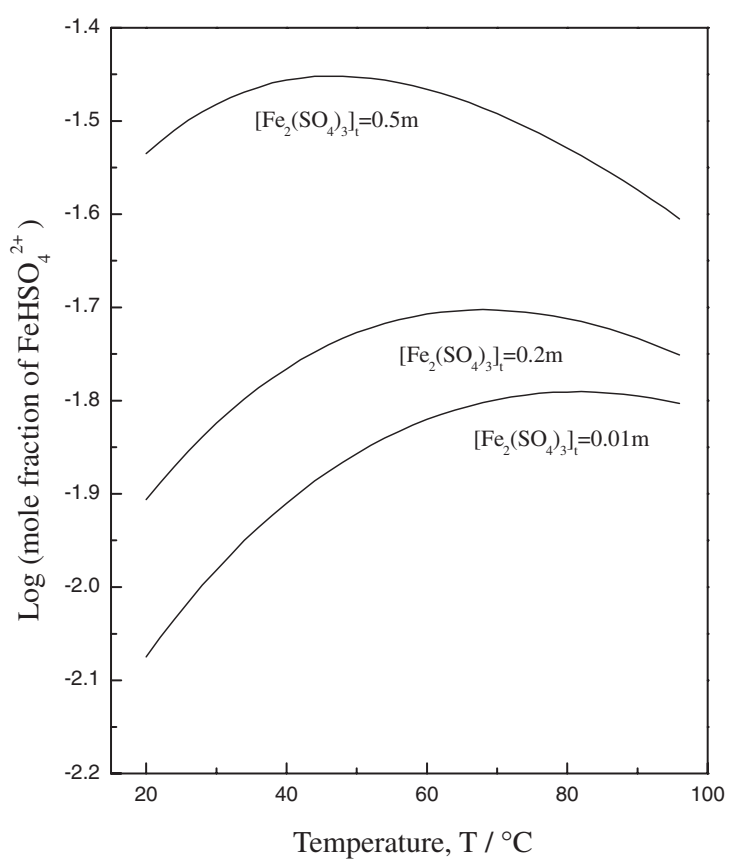

Fig. 5 Variation of mole fraction of $\mathrm{FeHSO}_{4}{ }^{+}$with temperature. $\left(\left[\mathrm{ZnSO}_{4}\right]_{\mathrm{t}}=1.0 \mathrm{~m},\left[\mathrm{H}_{2} \mathrm{SO}_{4}\right]_{\mathrm{t}}=0.5 \mathrm{~m},[\mathrm{NaOH}]_{\mathrm{t}}=0.3 \mathrm{~m}\right)$.

\section{temperature.}

Figures 4 and 5 show the variation of the mole fraction of $\mathrm{Fe}\left(\mathrm{SO}_{4}\right)_{2}{ }^{-}$and $\mathrm{FeHSO}_{4}{ }^{2+}$ with increasing concentration of $\mathrm{Fe}_{2}\left(\mathrm{SO}_{4}\right)_{3}$ and temperature of the solution, in which the concentration of $\mathrm{ZnSO}_{4}$, is $0.1 \mathrm{~m}, \mathrm{H}_{2} \mathrm{SO}_{4} 0.5 \mathrm{~m}$ and $\mathrm{NaOH}$ $0.3 \mathrm{~m}$, respectively. Figure 4 reveals that the mole fraction of $\mathrm{Fe}\left(\mathrm{SO}_{4}\right)_{2}{ }^{-}$increases with increasing temperature and reaches a maximum and then decreases with further increase of temperature. It is also shown that the mole fraction of 
$\mathrm{Fe}\left(\mathrm{SO}_{4}\right)_{2}{ }^{-}$increases greatly with increasing concentration of $\mathrm{Fe}_{2}\left(\mathrm{SO}_{4}\right)_{3}$. Figure 5 shows the effects of solution temperature and $\mathrm{Fe}_{2}\left(\mathrm{SO}_{4}\right)_{3}$ concentration on the mole fraction of $\mathrm{FeHSO}_{4}{ }^{2+}$. It is known from Figs. 4 and 5 that the variation of mole fraction of $\mathrm{FeHSO}_{4}{ }^{2+}$ and $\mathrm{Fe}\left(\mathrm{SO}_{4}\right)_{2}{ }^{-}$with solution temperature and $\mathrm{Fe}_{2}\left(\mathrm{SO}_{4}\right)_{3}$ concentration is similar to each other in the range investigated in this study.

Majima et al. calculated the mean activity coefficients of $\mathrm{Fe}_{2}\left(\mathrm{SO}_{4}\right)_{3}$ in the $\mathrm{Fe}_{2}\left(\mathrm{SO}_{4}\right)_{3}-\mathrm{H}_{2} \mathrm{SO}_{4}-\mathrm{H}_{2} \mathrm{O}$ system at $25^{\circ} \mathrm{C}$ by applying McKay-Perring method and these values are represented in Fig. 6. ${ }^{13)}$ Also the mean activity coefficients of $\mathrm{Fe}_{2}\left(\mathrm{SO}_{4}\right)_{3}$ calculated in this work by the following equation are shown in Fig. 6.

$$
\gamma_{ \pm, \mathrm{Fe}_{2}\left(\mathrm{SO}_{4}\right)_{3}}=\left[\left(\gamma_{\mathrm{Fe}^{3+}}\right)^{2}\left(\gamma_{\mathrm{SO}_{4}^{2-}}\right)^{3}\right]^{1 / 5}
$$

Figure 6 reveals that the absolute values of $\gamma_{ \pm, \mathrm{Fe}_{2}\left(\mathrm{SO}_{4}\right)_{3}}$ calculated in this work differ from those reported by Majima but both of them had the same tendency of variations with the concentration of $\mathrm{H}_{2} \mathrm{SO}_{4}$ and $\mathrm{Fe}_{2}\left(\mathrm{SO}_{4}\right)_{3}$. It is seen in Fig. 6 that $\gamma_{ \pm, \mathrm{Fe}_{2}\left(\mathrm{SO}_{4}\right)_{3}}$ decrease to reach a minimum and then increase with increasing concentration of $\mathrm{H}_{2} \mathrm{SO}_{4}$, when $\mathrm{Fe}_{2}\left(\mathrm{SO}_{4}\right)_{3}$ concentration is $0.1 \mathrm{~m}$. On the contrary, $\gamma_{ \pm, \mathrm{Fe}_{2}\left(\mathrm{SO}_{4}\right)_{3}}$ simply increases with $\mathrm{H}_{2} \mathrm{SO}_{4}$ concentration when $\mathrm{Fe}_{2}\left(\mathrm{SO}_{4}\right)_{3}$ concentration is $0.5 \mathrm{~m}$.

Table 5 shows the compositions of the $\mathrm{ZnSO}_{4}-\mathrm{Fe}_{2}\left(\mathrm{SO}_{4}\right)_{3}$ $\mathrm{Na}_{2} \mathrm{SO}_{4}-\mathrm{H}_{2} \mathrm{SO}_{4}-\mathrm{NaOH}-\mathrm{H}_{2} \mathrm{O}$ system and experimental $\mathrm{pH}$ values at 25,50 and $75^{\circ} \mathrm{C}$. The values of $\mathrm{pH}$ and ionic strength calculated in this study at various temperatures are also shown in Table 5. The absolute difference of $\mathrm{pH}$ values between measured and calculated is represented in Fig. 7. It is also seen in Fig. 7 that the difference becomes larger with increasing ionic strength and temperature of the electrolyte solution. The ionic strength of the solution was evaluated to be $7.8 \mathrm{~m}$, assuming that the solution possessing the following composition dissociated completely into their constituents;
Table 5 Experimental and predicted results for $\mathrm{ZnSO}_{4}-\mathrm{Fe}_{2}\left(\mathrm{SO}_{4}\right)_{3}$ $\mathrm{Na}_{2} \mathrm{SO}_{4}-\mathrm{H}_{2} \mathrm{SO}_{4}-\mathrm{NaOH}-\mathrm{H}_{2} \mathrm{O}$ system.

(unit: molality)

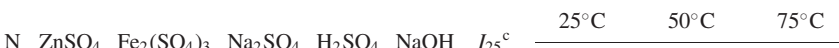
\begin{tabular}{lllllll}
\hline $\mathrm{pH}$ & $\mathrm{pH}^{\mathrm{c}}$ & $\mathrm{pH}$ & $\mathrm{pH}^{\mathrm{c}}$ & $\mathrm{pH}$ & $\mathrm{pH}^{\mathrm{c}}$
\end{tabular}

\begin{tabular}{lllllllllllll}
\hline 1 & 0.149 & 0.0871 & 0.137 & 0.199 & 0.122 & 2.44 & 1.05 & 1.14 & 1.19 & 1.31 & 1.38 & 1.48
\end{tabular}

\begin{tabular}{lllllllllllll}
\hline 2 & 0.149 & 0.0871 & 0.137 & 0.199 & 0.243 & 2.56 & 1.38 & 1.42 & 1.55 & 1.59 & 1.79 & 1.76
\end{tabular}

\begin{tabular}{lllllllllllll}
\hline 3 & 0.149 & 0.0871 & 0.137 & 0.298 & 0.122 & 2.55 & 0.78 & 0.87 & 0.91 & 1.03 & 1.04 & 1.19
\end{tabular}

\begin{tabular}{lllllllllllll}
\hline 4 & 0.149 & 0.0871 & 0.137 & 0.298 & 0.243 & 2.67 & 0.94 & 1.02 & 1.13 & 1.19 & 1.32 & 1.36
\end{tabular}

\begin{tabular}{lllllllllllll}
\hline 5 & 0.149 & 0.0871 & 0.137 & 0.397 & 0.122 & 2.67 & 0.69 & 0.69 & 0.80 & 0.84 & 0.88 & 0.98
\end{tabular}

\begin{tabular}{lllllllllllll}
\hline 6 & 0.149 & 0.0871 & 0.137 & 0.397 & 0.243 & 2.78 & 0.79 & 0.80 & 0.89 & 0.95 & 1.06 & 1.11
\end{tabular}

\begin{tabular}{lllllllllllll}
\hline 7 & 0.149 & 0.0871 & 0.137 & 0.298 & 0.365 & 2.78 & 1.18 & 1.23 & 1.36 & 1.40 & 1.61 & 1.57
\end{tabular}

\begin{tabular}{lllllllllllll}
\hline 8 & 0.149 & 0.0871 & 0.137 & 0.496 & 0.122 & 2.80 & 0.53 & 0.55 & 0.62 & 0.69 & 0.75 & 0.82
\end{tabular}

\begin{tabular}{lllllllllllll}
\hline 9 & 0.149 & 0.0871 & 0.137 & 0.496 & 0.243 & 2.90 & 0.63 & 0.64 & 0.72 & 0.78 & 0.84 & 0.93
\end{tabular}

\begin{tabular}{lllllllllllll}
\hline 10 & 0.149 & 0.0871 & 0.137 & 0.397 & 0.487 & 3.00 & 1.06 & 1.09 & 1.24 & 1.26 & 1.51 & 1.43
\end{tabular}

\begin{tabular}{lllllllllllll}
\hline 11 & 0.149 & 0.0871 & 0.137 & 0.496 & 0.487 & 3.11 & 0.85 & 0.84 & 1.01 & 1.01 & 1.21 & 1.17
\end{tabular}

\begin{tabular}{lllllllllllll}
\hline 12 & 0.149 & 0.0871 & 0.137 & 0.496 & 0.730 & 3.33 & 1.23 & 1.16 & 1.44 & 1.34 & 1.61 & 1.51
\end{tabular}

\begin{tabular}{lllllllllllll}
\hline 13 & 0.693 & 0.0811 & 0.128 & 0.185 & 0.113 & 4.56 & 1.02 & 1.19 & 1.20 & 1.36 & 1.47 & 1.52
\end{tabular}

\begin{tabular}{lllllllllllll}
\hline 14 & 0.693 & 0.0811 & 0.128 & 0.277 & 0.113 & 4.65 & 0.78 & 0.93 & 0.91 & 1.10 & 1.13 & 1.26
\end{tabular}

\begin{tabular}{lllllllllllll}
\hline 15 & 0.693 & 0.0811 & 0.128 & 0.185 & 0.226 & 4.67 & 1.30 & 1.45 & 1.46 & 1.63 & 1.68 & 1.79
\end{tabular}

\begin{tabular}{lllllllllllll}
\hline 16 & 0.693 & 0.0811 & 0.128 & 0.369 & 0.113 & 4.74 & 0.61 & 0.75 & 0.74 & 0.92 & 0.92 & 1.07
\end{tabular}

\begin{tabular}{lllllllllllll}
\hline 17 & 0.693 & 0.0811 & 0.128 & 0.277 & 0.226 & 4.75 & 0.93 & 1.07 & 1.11 & 1.24 & 1.30 & 1.40
\end{tabular}

\begin{tabular}{lllllllllllll}
\hline 18 & 0.693 & 0.0811 & 0.128 & 0.462 & 0.113 & 4.84 & 0.49 & 0.62 & 0.55 & 0.78 & 0.69 & 0.93
\end{tabular}

\begin{tabular}{lllllllllllll}
\hline 19 & 0.693 & 0.0811 & 0.128 & 0.369 & 0.226 & 4.84 & 0.71 & 0.85 & 0.83 & 1.02 & 1.09 & 1.18
\end{tabular}

\begin{tabular}{lllllllllllll}
\hline 20 & 0.693 & 0.0811 & 0.128 & 0.277 & 0.339 & 4.86 & 1.16 & 1.26 & 1.37 & 1.44 & 1.60 & 1.60
\end{tabular}

\begin{tabular}{lllllllllllll}
\hline 21 & 0.693 & 0.0811 & 0.128 & 0.462 & 0.226 & 4.94 & 0.55 & 0.69 & 0.70 & 0.86 & 0.82 & 1.01
\end{tabular}

\begin{tabular}{lllllllllllll}
\hline 22 & 0.693 & 0.0811 & 0.128 & 0.369 & 0.453 & 5.05 & 1.03 & 1.12 & 1.24 & 1.30 & 1.47 & 1.46
\end{tabular}

\begin{tabular}{lllllllllllll}
\hline 23 & 0.693 & 0.0811 & 0.128 & 0.462 & 0.453 & 5.15 & 0.80 & 0.88 & 1.00 & 1.06 & 1.17 & 1.22
\end{tabular}

\begin{tabular}{lllllllllllll}
\hline 24 & 0.693 & 0.0811 & 0.128 & 0.462 & 0.679 & 5.35 & 1.12 & 1.19 & 1.33 & 1.37 & 1.60 & 1.53
\end{tabular}

\begin{tabular}{lllllllllllll}
\hline 25 & 1.257 & 0.221 & 0.116 & 0.335 & 0.103 & 8.99 & 0.55 & 0.79 & 0.62 & 0.98 & 0.72 & 1.15
\end{tabular}

\begin{tabular}{lllllllllllll}
\hline 26 & 1.257 & 0.211 & 0.116 & 0.419 & 0.103 & 9.07 & 0.41 & 0.66 & 0.43 & 0.84 & 0.58 & 1.02
\end{tabular}

\begin{tabular}{lllllllllllll}
\hline 27 & 1.257 & 0.211 & 0.116 & 0.335 & 0.206 & 9.09 & 0.61 & 0.88 & 0.70 & 1.07 & 0.86 & 1.24
\end{tabular}

\begin{tabular}{lllllllllllll}
\hline 28 & 1.257 & 0.211 & 0.116 & 0.419 & 0.206 & 9.17 & 0.51 & 0.73 & 0.60 & 0.92 & 0.70 & 1.09
\end{tabular}

\begin{tabular}{lllllllllllll}
\hline 29 & 1.257 & 0.211 & 1.157 & 0.419 & 0.411 & 12.31 & 0.61 & 0.79 & 0.85 & 1.01 & 1.13 & 1.21
\end{tabular}

Superscript (c: calculated)

$\left[\mathrm{ZnSO}_{4}\right]=1.0 \mathrm{~mol} / \mathrm{kg},\left[\mathrm{Fe}_{2}\left(\mathrm{SO}_{4}\right)_{3}\right]=0.2 \mathrm{~mol} / \mathrm{kg},\left[\mathrm{H}_{2} \mathrm{SO}_{4}\right]$ $=0.5 \mathrm{~mol} / \mathrm{kg},[\mathrm{NaOH}]=0.2 \mathrm{~mol} / \mathrm{kg}$. At this ionic strength value, Fig. 7 shows that the absolute difference of $\mathrm{pH}$ will be 0.2 . Considering that a lot of additional reactions occur in the leaching solutions of zinc calcine, it seems that the experimental $\mathrm{pH}$ values agreed well with these calculated in the range of $2.5-9 \mathrm{~m}$ ionic strength of solution.

\section{Conclusions}

By developing a chemical model of $\mathrm{ZnSO}_{4}-\mathrm{Fe}_{2}\left(\mathrm{SO}_{4}\right)_{3}-$ $\mathrm{Na}_{2} \mathrm{SO}_{4}-\mathrm{H}_{2} \mathrm{SO}_{4}-\mathrm{NaOH}-\mathrm{H}_{2} \mathrm{O}$ system, the following conclusions were obtained:

(1) Ionic equilibria for the system were analyzed with the chemical equilibria, mass and charge balance equations taken into account. The activity coefficients and water activity were calculated by using the Pitzer equation.

(2) By applying Edwards' estimation method, the interaction parameters of individual ions were obtained from the interaction parameters of strong electrolytes given by Pitzer and Millero.

(3) The equilibrium concentrations and the activity coef-
Fig. 6 Effect of $\mathrm{H}_{2} \mathrm{SO}_{4}$ concentration on the mean activity coefficient of $\mathrm{Fe}_{2}\left(\mathrm{SO}_{4}\right)_{3}$ in the absence of $\mathrm{ZnSO}_{4}$ at $25^{\circ} \mathrm{C}$. 


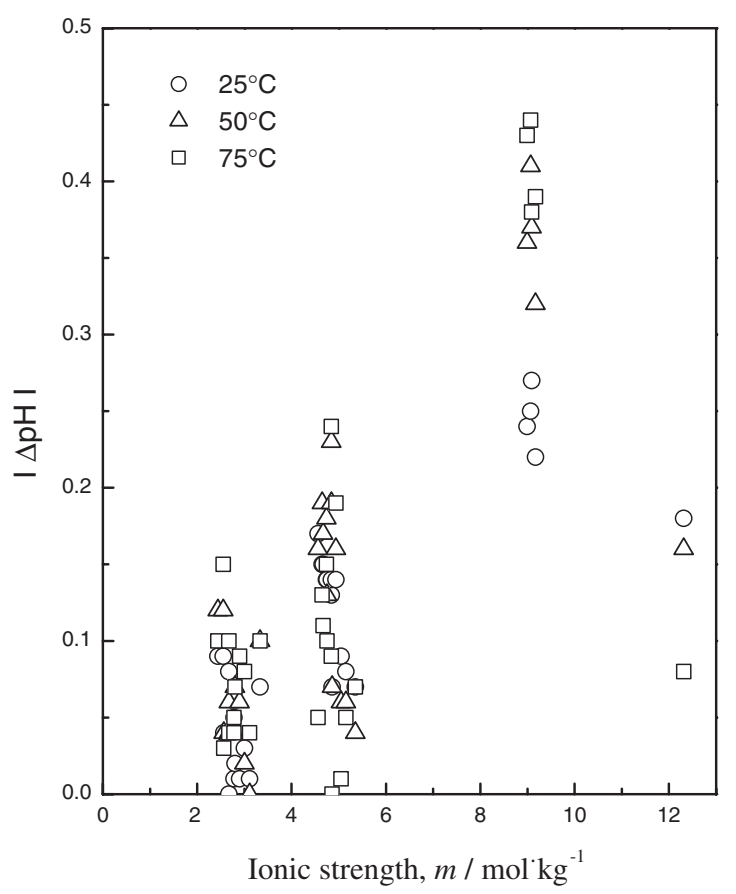

Fig. 7 Effect of ionic strength on the absolute difference in the $\mathrm{pH}$ values between experimentally measured and calculated in this study.

ficients of chemical species were calculated from the compositions of electrolyte solutions by using the model developed in this study. In the ranges of 2-9 $\mathrm{m}$ ionic strength and $25-75^{\circ} \mathrm{C}$ of solution, the calculated $\mathrm{pH}$ values were in good agreement with those measured experimentally.

(4) The mole fractions of chemical species containing hydroxide ions increase with increasing temperature because of the increase in solution $\mathrm{pH}$. The mole fraction of $\mathrm{Fe}\left(\mathrm{SO}_{4}\right)_{2}{ }^{-}$and $\mathrm{FeHSO}_{4}{ }^{2+}$ were greatly affected by the concentration of $\mathrm{Fe}_{2}\left(\mathrm{SO}_{4}\right)_{3}$ and solution temperature.

\section{REFERENCES}

1) C. K. Lee and L. L. Tavlarides: Polyhedron 4 (1985) 47-51.

2) D. Filippou, G. P. Demopoulos and V. G. Papangelakis: AIChE J. 41 (1995) 171-184.

3) W. Wang and D. B. Dreisinger: Metall. And Mater. Trans. B 29B (1998) 1157-1166.

4) J. F. Zemaitis, Jr D. M. Clark, M. Rafal and N. C. Scrivner: Handbook of aqueous electrolyte thermodynamics, (Design Institute for Physical Property Data, NY, 1986).

5) F. J. Millero, W. Yao and J. Aicher: Marine Chem. 50 (1995) 21-39.

6) Y. Zhang and M. Muhammed: Hydrometallurgy 60 (2001) 215-236.

7) W. Stumm and J. J. Morgan: Aquatic chemistry, (John Wiley \& Sons, INC., 1996) p. 273.

8) J. H. Bae and L. L Tavlarides: Metall. Trans. B 18B (1987) 399-407.

9) J. F. Zemaitis, Jr D. M. Clark, M. Rafal and N. C. Scrivner: Handbook of aqueous electrolyte thermodynamics, (DIPPR, NY, 1986) p. 503.

10) P. Marliacy, N. Hubert, L. Schuffenecker and R. Solimando: Fluid Phase Equilibria 148 (1998) 95-106.

11) J. F. Zemaitis, Jr D. M. Clark, M. Rafal and N. C. Scrivner: Handbook of aqueous electrolyte thermodynamics, (DIPPR, NY, 1986) pp. 179190.

12) T. J. Edwards, G. Maurer, J. Newmanand J. M. Prausnitz: AIChE J. 24 (1978) 966-976.

13) H. Majima and Y. Awakura: Metal. Trans. B 17B (1986) 621-627. 